\title{
TEORÍA DE LA ACCIÓN Y FUNDAMENTOS DE ECONOMÍA
}

\author{
JAVIER ARANZADI DEL CERRO*
}

Resumen. Este artículo parte de la teoría de la acción o praxeología de Mises para analizar la forma en que se proveen las necesidades económicas. Explica que la realidad económica se manifiesta en la acción personal en una sociedad y cultura determinadas. Es en la convivencia y en la participación común de unos valores, creencias, conocimientos, donde se configuran las estructuras de medios y fines que constituyen el quehacer de la economía.

Abstract. This paper sets out from Mises's theory of action or praxeology to analyze the way in which economic needs are provided for. It explains that economic reality is manifested in personal action in any one society and culture. It is in coexistence and the sharing of values, beliefs and knowledge that the structures of means and ends constituting the raw material of economics take shape.

Palabras clave: Escuela austríaca, praxeología, instituciones, cultura, ética.

Códigos JEL: A12, A14, B53, D69, Z13.

* Departamento de Análisis Económico: Teoría e Historia Económica, Facultad de Ciencias Económicas y Empresariales, Universidad Autónoma de Madrid. 


\section{INTRODUCCIÓN: \\ REALIDAD ECONÓMICA \\ Y ACCIÓN HUMANA}

Persona y acción están contenidas en todos y cada uno de los casos del actuar humano. ${ }^{1}$ Nada más obvio, para empezar, que reconocer que el hombre tiene necesidades que satisfacer. Es decir, hablar de realidad económica es hablar de necesidades. Necesita procurarse alimento, cobijo, pareja, etc. En nuestra sociedad, estamos habituados a proveer nuestras necesidades a través de los intercambios de mercado. Parémonos en la palabra hábito. No puedo negar el gusto que tengo por empezar siempre con la etimología de las palabras porque es un valioso hilo conductor de la investigación y el razonamiento. Hábito procede de héxis, la manera de habérselas con las cosas. Esta definición nos pone de manifiesto la forma en que nosotros nos manejamos con las cosas. Estamos acostumbrados a proveer nuestras necesidades mediante relaciones mercantiles; trabajamos por un salario que nos permite comprar aquello que deseamos.

Lo único que estamos poniendo de manifiesto es que el hombre hace cosas. Esta capacidad fabril es la que genera todo el abanico de posibilidades que tenemos a nuestra disposición. Es innegable que el desarrollo de la capacidad productiva de los últimos siglos ha generado un incremento de las posibilidades de acción nunca visto en la historia de la humanidad. Seguramente una persona del siglo pasado se quedaría sorprendida de la televisión, los viajes en avión, la informática, etc. Es tal la situación de cambio, que no es raro oír a una persona de cierta edad decir que el mundo ya no es lo que era. Ciertamente el mundo que se nos ofrece ahora es mucho más amplio y complejo que el de hace un siglo.

\footnotetext{
1 Véase K. Wojtyla (1982).
} 
Hemos escogido a propósito este ejemplo para poner de manifiesto algo que ya les rondará por la cabeza. Muchos pensarán que no hay ninguna necesidad para organizarse en economías de mercado y que, de hecho, hay otros regímenes económicos basados en la planificación y en el control estatal. Y están en lo cierto quienes así piensan. Pero si meditamos sobre lo que acabamos de decir nos encontramos con algo aparentemente paradójico. Comer, beber, vestirse, son necesidades esenciales al ser humano. Pero lo que ya no es tan esencial es la forma de satisfacerlas. Es decir, la estructura económica capitalista o la socialista no vienen determinadas por las necesidades que satisfacen. En otras palabras, no hay ninguna necesidad en la forma de satisfacer nuestras necesidades. Algo aparentemente paradójico, pero que era de esperar al estudiar personas. Si tratáramos sobre animales, atrapados en el mundo de los estímulos, no hablaríamos de economía. A nadie se le ocurre afirmar que el «trabajo» del león es cazar antílopes. En cambio, el hombre es cazador, agricultor, ganadero, ingeniero, etc. La economía es, por lo tanto, privativa del hombre. El hombre ha liberado su comportamiento del apremiante estímulo y ha intercalado entre éste y su respuesta el mundo de los valores, sentimientos, proyectos, etc. Se ha construido un mundo no sólo de estímulos, sino de pensamientos que dirigen su acción. Este abandono del salvajismo hace que la vida del hombre no se desarrolle entre cosas, sino entre cosas que son transfiguradas por el sentido que les otorgamos y, así, vivimos entre cosas-sentido. Entramos de lleno en el mundo simbólico de la cultura y la sociedad, que es el ámbito donde la economía adquiere su pleno sentido.

Podemos decir, por lo tanto, que el hombre está ligado a sus necesidades, pero la forma de ligarse a ellas no es meramente animal. ${ }^{2}$ No hay nada humano que sea completamente explicable

2 Señala A. Millán-Puelles: «Estar sujeto a unas necesidades básicas o primarias, que condicionan la posibilidad de atender a las otras, significa en el hombre estar dotado de un estrato animal a cuyas exigencias hay que proveer con unas 
recurriendo sólo a la naturaleza del ser vivo. Como bien señala Martin Buber, «ni siquiera el hambre del hombre es el hambre de un animal». ${ }^{3}$ El hombre se liga a sus necesidades a través del mundo simbólico que comparte con otros hombres y que se transmite socialmente. ${ }^{4}$ El hombre no viene determinado por la especie. Es esta la razón de la fragilidad del recién nacido, en comparación con la rapidez con que la cría de cualquier otro animal provee sus propias necesidades. La radical diferencia es que el hombre tiene que aprender y asimilar todo el entramado simbólico que la sociedad le trasmite y que le permitirá enfrentarse a la vida. Un ejemplo bien sencillo de este contraste nos lo ofrece la mano humana. ${ }^{5}$ Comparada con la pezuña del herbívoro, no tiene la dureza necesaria ni para huir velozmente, ni para golpear; comparada con la garra del carnívoro, no tiene ni el filo, ni la fuerza necesaria para desgarrar. Aparentemente, la mano no tiene ninguna función específica. Es un órgano indeterminado.

En realidad, la mano es una capacidad de acción: cojamos un palo. Con un palo se golpea más fuerte que con la mano. Pero un palo es inútil ante un animal grande, por ejemplo, un búfalo. El palo no ofrece, en sí, la solución. Pero la inventiva del hombre posibilita que si se afila el palo, se puede utilizar para herir al animal y alcanzar sus órganos vitales. El hombre trans-

capacidades y aptitudes que sobrepasan ese mismo estrato, precisamente porque lo pueden objetivar. Esta objetivización, imprescindible para que la economía sea un artificio, es algo que el animal irracional no puede hacer, y no porque no perciba los objetos de sus necesidades, sino porque no objetiva a éstas a su vez, por no contar con la capacidad de concebirlas. Respecto de ellas, su situación es la de estar «ligado», no «ob-ligado», ya que este $o b$ supone un trascenderlas — sin dejar de tenerlas- ya que implica el espíritu como capacidad de reflexión (auto-objetivización), esencialmente inviable para un ser desprovisto de la facultad de hacer conceptos.» Cf. A. Millán-Puelles (1984) p. 36. Cursivas en el original.

3 Véase M. Buber (1995) p. 80.

${ }^{4}$ Como señala E. Husserl: «Humanidad en general es, por esencia, ser hombre en humanidades vinculadas por la generación y la socialidad.» Cf. E. Husserl (1991) p. 16.

5 Este ejemplo lo tomamos de L. Polo (1993) p. 64. 
forma el palo en una lanza. El palo no es la lanza. El origen de la lanza es la transformación del palo en un símbolo cultural. El palo es naturaleza, pero la lanza es un símbolo de comportamiento inteligente, es cultura. La transformación de cosas en instrumentos consiste en actualizar las posibilidades de las cosas. La generación de una posibilidad afecta a todo el sistema de acción. La posibilidad de cazar animales más grandes exige palos de cierto grosor. Se investigan nuevas formas de endurecer las puntas utilizando el fuego. Lo más importante es que su utilización plantea nuevas preguntas. ¿Por qué una lanza es buena para cazar un búfalo y en cambio es ineficaz con animales más rápidos? La lanza es demasiado pesada para cazar gacelas. Hace falta algo más ligero. La solución se encontró en aligerar el peso de la lanza, creando la jabalina. Así, el hombre aplica su inteligencia a la práctica de la habilidad manual. Las manos se convierten en inventores de instrumentos cada vez más complejos. Aparece el arco y las flechas, se domestican animales, etc. Las manos se convierten en el instrumento de instrumentos ${ }^{6} \mathrm{y}$ en algo más importante. Para demostrar que una persona está desarmada, extiende la palma de la mano. La mano se convierte en un símbolo; entra de lleno en el mundo simbólico. Con la mano se realiza el símbolo de la paz. La mano en conjunción con la cara se vuelve expresiva. ${ }^{7}$

Esta innovación constante pone de relieve la importancia de la inventiva en la constitución de un sistema social. Primero se crea un nuevo instrumento. Luego se generaliza su uso. Y por último, se vuelve costumbre su uso. Es una costumbre trasmisible y como tal se entrega en tradición a las generaciones veni-

${ }^{6}$ Así definió Aristóteles la mano: el instrumento de instrumentos. Cf. Aristóteles, Acerca del alma, III, 432 a.

${ }^{7}$ La ciencia económica, popularmente, es la forma de ganar dinero. Es la crematística. Esta palabra procede de khrêma, que a su vez viene del verbo krháo, que significa tener en la mano. Según Leonardo Polo, el sentido primitivo de esta palabra está aludiendo a que el hombre es un ser con manos. Cf. L. Polo (1993) p. 64. 
deras. Podemos considerar que la realidad económica es un proceso de creación de posibilidades de acción que se realizan socialmente y se trasmiten culturalmente. Constituye parte de lo que E. Husserl denominó Lebenswelt (el mundo de la vida). Indicando ese entramado de relaciones y símbolos que el hombre hace socialmente y transmite en generaciones. Digamos, por lo tanto, que el hombre es un con-ser. Dando a entender que la esencia del hombre es ser-con. Es decir, que para constituirse como tal le es esencial otros hombres y la cultura. Como señala Zubiri: «este con (con las cosas, con los demás hombres, con-migo mismo) no es un añadido, una relación extrínseca que añade el hombre en el ejercicio de su vida. Esto sería absolutamente quimérico. Es algo mucho más radical. El con es un momento formal estructural de la misma vida, y por lo tanto de la sustantividad humana en su dinamismo vital.» ${ }^{8}$

Nuestro estudio de la economía en esta introducción se circunscribe en un ámbito muy determinado. Nos limitamos rigurosa y metódicamente a describir lo que las cosas son patentemente, es decir, cómo se nos manifiestan en el ámbito de la realidad radical primaria que es nuestra vida. Constatamos que la realidad económica se manifiesta en la acción personal en una sociedad y cultura determinadas. Es en la convivencia y en la participación común de unos valores, creencias, conocimientos, donde se configuran las estructuras de medios y fines que constituyen el quehacer de la economía. Es totalmente adecuado definir, por lo tanto, al hombre como con-ser. Señalando con esta expresión la esencial apertura de la persona a sus semejantes mediando la sociedad y la cultura. Es decir, toda acción individual es, de suyo, social; tiene un significado cultural. En resumen, el estudio de la economía, y de cualquier ciencia social en general, se fundamenta en el análisis de la acción.

\footnotetext{
${ }^{8}$ Cf. Zubiri (1989) p. 225. Cursivas en el original.
} 


\section{HACIA UNA TEORÍA GENERAL DE LA ACCIÓN}

Las ciencias sociales, sea Economía, Sociología, Psicología, Derecho, Ciencias Políticas, tienen como realidad objeto de estudio a la persona. Es importante resaltar el trabajo pionero realizado por el equipo dirigido por T. Parsons y E.S. Shills, con la colaboración de E.C. Tolman, G.W. Allport, C. Kluckhohn, H.A. Murray, R.R. Sears, R.C. Sheldon, S.A. Stouffer, publicado con el título Hacia una Teoría General de la Acción. ${ }^{9}$ Buscaban los elementos comunes de las distintas áreas de investigación de los miembros del equipo. Si tenemos en cuenta la distinta procedencia de los miembros, había sociólogos, psicólogos y antropólogos sociales, y la relevancia de sus trabajos en sus áreas respectivas de trabajo, es razonable que considerasen su trabajo como «una base para el desenvolvimiento de las ciencias sociales en general». ${ }^{10}$ Dado el relieve de los miembros de dicho grupo, y la relevancia que dentro de las ciencias sociales ha tenido Hacia una Teoría General de la Acción, resumamos brevemente sus ideas. Este resumen nos presentará una primera teoría explicativa de la realidad expuesta en la introducción, y nos permitirá esbozar los elementos a desarrollar en este artículo.

La tesis principal expuesta en Hacia una Teoría General de la Acción es que el hombre se esfuerza por alcanzar metas. En su búsqueda de metas, el actor se orienta hacia los objetos y esta orientación se supone que comprende tres modos: el cognoscitivo, el catéctico (desiderativo) y el evaluativo. Estos tres elementos conforman un sistema, ya que «los elementos cognizados son

9 La obra original lleva por título Towards a General Theory of Action (Nueva York: Harper \& Row, 1962). Las referencias en el cuerpo del texto se toman de la versión española, Hacia una Teoría General de la Acción (Buenos Aires: Editorial Kapeluzz, 1968).

10 Op, cit., p. 14. 
evaluados según ayuden o no a conseguir lo que el actor desea». ${ }^{11}$

La teoría de Parsons integra los tres elementos explicativos en un sistema. Un sistema, afirma Parsons, «se caracteriza por la interdependencia de sus partes o variables. La interdependencia se refiere a la existencia de relaciones determinadas entre las partes o variables, en lugar de variaciones al azar. En otras palabras, la interdependencia es un orden en las relaciones entre los componentes que participan en la formación del sistema.» ${ }^{12}$ Los elementos desiderativos, cognitivos y evaluativos están internamente relacionados. La explicación de cada uno de ellos requiere la presencia de los otros dos. Es decir, la teoría de la acción se estructura en tres partes: desiderativa, cognitiva y evaluativa, que representan un orden entre sí. Estas tres partes constitutivas definen un sistema de acción. Démosle la vuelta al argumento y preguntemos, ¿cuántas estructuras en la realidad cumplen estos tres requisitos y se las pueden considerar, por tanto, sistemas de acción?

Según Parsons, hay tres tipos de sistemas que presentan los tres elementos mencionados:

- Las personas: son sistemas de acción motivada que se organizan alrededor de los organismos vivientes.

- Los sistemas sociales: son sistemas de acción que se organizan alrededor de las relaciones mutuas de los actores.

- Los sistemas culturales: son sistemas de patrones simbólicos (estos patrones son creados o manifestados por los actores individuales y se trasmiten en el sistema social por difusión y en las personalidades por medio del aprendizaje). ${ }^{13}$

\footnotetext{
11 Op, cit., p. 198.

12 Op, cit., p. 133

13 Op, cit., p. 176.
} 
Así dicho, parece que estos tres sistemas son realidades distintas. Parsons se encarga de desmentirlo: «la personalidad, la cultura y el sistema social son analíticamente inseparables y cada uno de los tres implica a los otros dos. Si hay algo emergente, es la acción, como categoría que abarca a las tres y ella emerge del mundo orgánico.» ${ }^{14}$ Ahora bien, si estos elementos son analíticamente inseparables, tendrán que tener unas reglas de integración que garanticen estabilidad al sistema. Analizando la obra de Parsons, el control e integración de la acción recae sobre la norma moral. ¿Qué entiende Parsons por norma de valor moral? Afirma: «las normas de valor moral son la mayoría de las normas comprehensivas e integrativas para determinar y regular el sistema total de acción... Ellas constituyen el tribunal de última instancia en cualquier problema integrativo dentro del sistema». ${ }^{15}$

La indicación de este texto apunta a la posibilidad de la existencia de una teoría moral o ética integrativa o sistémica que controle las distintas partes de la estructura constitutiva de la acción. Más indicaciones sobre esta teoría ética y sobre cuál es la relación de las partes constituyentes no se aportan con claridad en Hacia una Teoría General de la Acción.

En este trabajo no nos vamos a centrar en la ética. Nuestro objetivo será centrarnos en las conclusiones a las que llega Parsons. Así, afirma, que el objetivo principal ha sido la descripción, «de los complejos conceptos descriptivos de la estructura de la acción». ${ }^{16}$ Ahora bien, Parsons es consciente de que estos conceptos tienen «hipótesis dinámicas implícitas». ${ }^{17}$

Con el siguiente esquema podemos representar los elementos analíticos aportados por Parsons y los interrogantes que plantea su integración:

\footnotetext{
14 Op, cit., p. 278

15 Op, cit., p. 97.

16 Op, cit., p. 273

17 Op, cit., p. 273
} 
El esquema representa los tres subsistemas de acción que distingue Parsons: la persona (situada en el centro del esquema) inserta en una sociedad con una cultura (elementos representados a la izquierda), genera la acción (representada por la flecha que surge de la confluencia de los tres subsistemas). Las flechas dobles representan las relaciones de interdependencia que existen entre la sociedad, la cultura y la persona. La obra de Parsons se ha centrado en la descripción de los subsistemas, sin desarrollar la estructura dinámica que existe entre los componentes del sistema. Esta relación tripartita se nos ha manifestado en la introducción al concluir que el hombre es un con-ser. Señalando con esta expresión la esencial apertura de la persona a sus semejantes mediando la sociedad y la cultura. Es decir, toda acción individual es, de suyo, social; tiene un significado cultural. Pero, no nos vamos centrar, en este trabajo, en analizar las relaciones entre sociedad, cultura y acción individual.

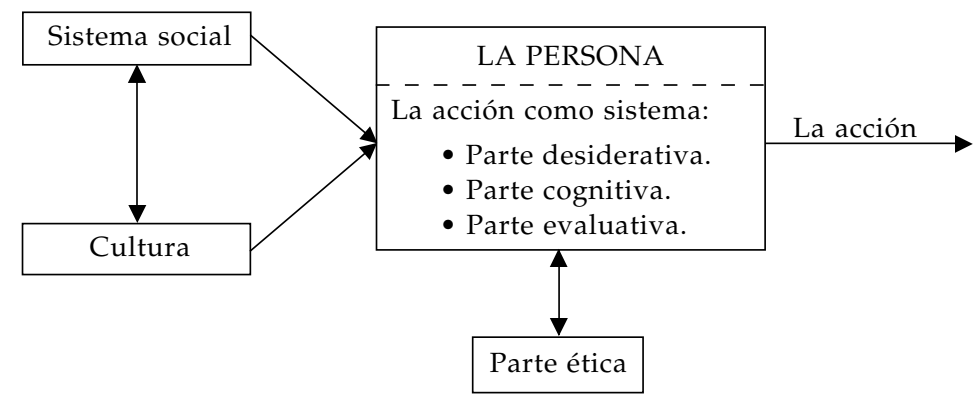

Nuestro objetivo será analizar el dinamismo de la acción individual. Es decir, hacer explícitos los dinamismos implícitos que Parsons consideraba. También representamos el elemento ético que Parsons considera el regulador del sistema. La relación de la ética con el resto del sistema no queda clara en Hacia una Teoría General de la Acción, por lo que sería pertinente interrogarnos por la relación de la ética con la estructura dinámica de la acción. 
Aunque, como ya hemos mencionado, el análisis de la ética dentro de la teoría de la acción excede el alcance de este trabajo. ${ }^{18}$

En resumen, el objetivo del presente artículo es analizar la relación entre los elementos desiderativos, cognitivos y evaluativos presentes en la acción individual. Es decir, estudiar el dinamismo interno al que apunta Parsons. Se plantean, por lo tanto, las dos preguntas siguientes:

1. ¿Cuál es la relación entre los elementos desiderativos, cognitivos y evaluativos presentes en la acción individual? Y, como corolario,

2. ¿Cuáles son las posibilidades reales de acción de la persona?

\section{TEORÍA ECONÓMICA Y TEORÍA \\ DE LA ACCIÓN: LA ACCIÓN HUMANA \\ EN L. VON MISES}

La exposición de la obra de Parsons aporta un marco común para las ciencias sociales, y nos ha permitido formular las dos preguntas que constituyen el núcleo de este trabajo. La realidad económica muestra las características que el modelo teórico de Parsons quiere explicar. La realidad económica es, de suyo, dinámica y compleja. Consideramos, por lo tanto, esencial la aportación de Parsons sobre las ciencias sociales. Su aportación básica es poner de manifiesto la necesidad de sistemas analíticos que permitan presentar todas las características esenciales del objeto de estudio, y segundo, permitir desarrollos teóricos que desvelen las relaciones dinámicas de dichos elementos.

Una vez demostrada la necesidad teórica de interrogarse sobre los fundamentos antropológicos de la economía, nos queda una pregunta que nos permitirá canalizar la investigación.

\footnotetext{
18 Se puede consultar sobre el tema Aranzadi, J. (1997) (1999b) (2001).
} 
¿Aporta la teoría económica algún modelo que se planteara la riqueza de la realidad económica basándose en una teoría de la acción? La respuesta a esta pregunta es afirmativa y constituirá el desarrollo de este apartado exponer la obra teórica de L. von Mises, cuyo objetivo era basar la ciencia económica en una teoría general de la acción. Lo cual mostrará cómo se relacionan internamente los elementos desiderativos, cognitivos y evaluativos en la acción individual. ${ }^{19}$

Las obras de Mises dedicadas a la fundamentación de la economía, por orden cronológico, son:

- Epistemological Problems of Economics ${ }^{20}$

- La Acción Humana ${ }^{21}$

- Teoría e historia ${ }^{22}$

- The Ultimate Foundation of Economic Science. ${ }^{23}$ Último libro de Mises, publicado a la edad de 81 años.

19 Sobre la teoría de la acción de Mises y sus desarrollos teóricos puede consultarse J. Aranzadi (1999a).

${ }^{20}$ Este libro se publicó por primera vez en alemán en 1933. Actualmente es asequible la traducción inglesa que, con el título señalado, fue publicada por New York University Press, Nueva York, 1981.

${ }^{21}$ La Acción Humana tiene tres ediciones en inglés escritas por Mises con el título Human Action: A Treatise on Economics. Las dos primeras ediciones publicadas por Yale University Press, New Haven en 1949 y 1963, respectivamente, y la tercera por Henry Regnery, Chicago, 1966. Esta obra ha tenido siete ediciones en español. La primera, editada por la Fundación Ignacio Villalonga, Valencia, 1960 fue traducida de la tercera edición inglesa por Joaquín Reig Albiol. La segunda fue editada por Sopec, Madrid, 1968. Las ediciones restantes han corrido a cargo de Unión Editorial, Madrid, años 1980, 1985, 1995, 2001 y 2004, respectivamente. A partir de la quinta edición, con un amplio «Estudio Preliminar» de Jesús Huerta de Soto, presenta una notable corrección estilística respecto a las anteriores, por lo que todas las citas de este estudio se extraerán de la última.

${ }^{22}$ Obra aparecida en inglés con el título Theory and History (Yale: Yale University Press, 1957 y reimpresa en 1969 por Arlington House, New Rochelle. Existe traducción española realizada por Rigoberto Juárez y publicada con el título Teoría e Historia (Madrid: Unión Editorial, 1. ${ }^{a}$ ed., 1975; 2. ${ }^{\text {a }}$ ed., 2003). Las citas están tomadas de esta segunda edición española editada dentro de la colección «Biblioteca Austriaca».

${ }^{23}$ Obra aparecida en inglés con el título Ultimate Foundation of Economic Science: An Essay on Method. Existen dos ediciones de la obra en inglés. La primera publicada por William Volker Fund, Indianápolis, 1962 y la segunda por Sheed Andrews and McMeel, Kansas, 1978. Nosotros utilizaremos la segunda edición. 
El propio Mises consideraba sus obras más importantes $L a$ Acción Humana y Teoría e Historia. Siendo en su opinión, The Ultimate Foundation of Economic Science «un suplemento y un comentario a dichas obras». ${ }^{24}$ La Acción Humana es un libro claramente dividido en dos partes: la primera parte desarrolla las categorías básicas de toda acción humana: es un tratado de praxeología, palabra acuñada por Mises de la raíz griega prâxis, acción. La segunda parte es una teoría del mercado y del cálculo económico, cataláctica en la terminología misiana (palabra originaria del griego katallattein, cuya traducción es canjear o permutar).

Es importante resaltar esta estructura de la obra para aclarar un error bastante común al aproximarse a la obra de Mises. La ciencia económica para Mises es la cataláctica, el intercambio de bienes de forma directa, mercancía-mercancía o indirecta, mercancía-dinero-mercancía, sujeto a cálculo económico. La praxeología es la teoría de los prerrequisitos, requisitos y categorías de toda acción humana. Al ser las acciones de mercado un caso particular dentro de las acciones posibles, la praxeología engloba a la cataláctica. Mises explicaba esta relación entre ambos ámbitos de acción con la siguiente frase: «la teoría de la acción o praxeología y su rama más desarrollada la economía o cataláctica». Nunca escribió Mises que la praxeología fuese la economía.

La explicación de por qué considera Mises correcta la inclusión de la cataláctica en la praxeología la realiza en Epistemological Problems of Economics, al ampliar el ámbito de la teoría subjetiva del valor para criticar la diferenciación entre comportamiento económico y no-económico de la escuela clásica.

Son éstas las razones por las que consideramos fundamental para la comprensión de la obra de Mises Epistemological Problems of Economics. Es en esta obra donde se plantean las limitaciones que la caracterización del agente económico clásico implica para la explicación de los fenómenos económicos, y las vías de desa-

\footnotetext{
${ }^{24}$ Véase Mises (1978) p. XIII.
} 
rrollo teórico que, siguiendo los pasos de Carl Menger y BöhmBawerk, amplían el subjetivismo de la teoría del valor, incardinando las acciones económicas dentro de una teoría general de la acción humana.

\section{Desarrollo de la teoría subjetiva del valor}

Para superar la distinción de los economistas clásicos entre racionalidad o comportamiento económico e irracionalidad o comportamiento no-económico, Mises empieza Epistemological Problems of Economics con un estudio del objetivo y campo de la ciencia de la acción humana. Comienza por establecer el carácter lógico de «la ciencia universalmente válida de la acción humana». ${ }^{25} \mathrm{El}$ concepto básico de acción y sus requisitos. Este apartado es importante. Define por primera vez la acción humana «o como se la designa tautológicamente, acción racional... como comportamiento racional». ${ }^{26}$

El prerrequisito para la acción es un estado de insatisfacción y la posibilidad de cambiar esta situación. El fin que nos motiva a actuar, continúa Mises, viene dado desde fuera de la acción. Es un sentimiento, una percepción subjetiva de una situación que mediante la acción es mejorable. En resumidas cuentas, es un juicio de valor. La ciencia, la explicación racional, no tiene nada que decir sobre lo que se debe o no se debe desear. De esto se encargan las normas o la ética. El economista sólo debe constatar la existencia de una insatisfacción que mueve a la acción. Afirma Mises que la elección de los medios se basa en la apreciación individual sobre su adecuación para la obtención del fin. Un individuo puede equivocarse y no utilizar los medios adecuados. No es irracional, simplemente ha errado. Si una persona cambia frecuentemente de fines no es irracional, sino inconstante. Si no utiliza los medios adecuados ha fallado. Por lo tanto, toda acción es racional.

\footnotetext{
${ }^{25}$ Véase Mises (1981) p. 13 y ss.
}

${ }^{26}$ Op. cit., p. 23. 
Es errónea, argumenta Mises, la división de «lo económico» y «lo no-económico» en función de los fines o de la adecuación de los medios a la consecución de los mismos. Nuestro objetivo no es juzgar los fines o los medios, sino estudiar el proceso por el cual el actor crea la estructura de medios y fines. El principio económico no puede basarse en los fines, ya que éstos están fuera de la economía. Por su parte, los medios no permiten obtener un principio económico, ya que la elección de los mismos es el resultado de una apreciación subjetiva del actor. Con estas consideraciones, Mises desecha la obtención de un principio económico a través de la clasificación de los fines o los medios.

La búsqueda de dicho principio le lleva a Mises a interrogarse por la esencia del comportamiento económico. Si la economía estudia la utilización de medios para la consecución de fines, independientemente de cuales sean dichos fines y medios, el principio económico ha de ser algo más radical que la elección de los fines y los medios. Este principio es la realidad de tener que descubrir una estructura de medios y fines; de tener que elegir entre fines y optar por uno, renunciando a los otros. El principio económico es «la existencia de conflicto entre los fines y por lo tanto la necesidad de elegir entre ellos». ${ }^{27}$

Es decir, si toda acción implica una elección entre diversas posibilidades, toda acción es economizadora con los medios disponibles para la realización de los fines alcanzables. Por lo tanto, la ley fundamental de la acción es el principio económico. Toda acción está bajo su dominio. «El que quiera negar la posibilidad de la ciencia económica tiene que empezar por cuestionar la validez universal del principio económico, es decir, la necesidad de economizar, como característica de toda acción, por su propia naturaleza. ${ }^{28}$

\footnotetext{
27 Véase Mises (1981) p. 79.

28 Op. cit., p. 80.
} 
Esta definición de economía plantea problemas de inmediato. Problemas a los que no fue ajeno Mises. Por un lado, le permite atacar al homo oeconomicus clásico. Esta abstracción clásica comprende sólo un lado del hombre, «el económico, el material. Le considera sólo un hombre envuelto en negocios, no como un consumidor de bienes. ${ }^{29}$ Por otro lado, Mises, ¿no había dicho que toda acción es por su naturaleza económica? ¿Por qué critica al homo oeconomicus clásico por fijarse sólo en lo económico, si lo económico abarca todo? $?^{30}$

Para explicar esta situación hay que introducir dos conceptos que utilizaba Mises: «lo económico en sentido amplio» $\mathrm{y}$ «lo económico en sentido estricto». El primer término se refiere al ámbito general de la acción que cumple el principio económico. El segundo término se refiere a aquellas acciones sujetas a las consideraciones monetarias de coste-beneficio. Afirma Mises: «[L]a característica especial del cálculo económico es que la esfera de su utilización nos parece una provincia especial dentro del dominio más amplio de toda acción. En el uso diario, la esfera de la economía se extiende hasta donde es posible el cálculo monetario. Lo que va más allá es considerado la esfera no-económica... Considerando el cálculo económico en términos monetarios como el más importante e indispensable instrumento para la producción en gran escala nos demuestra la falta de sentido de una separación terminológica entre estas dos esferas.» ${ }^{31}$

Estos dos conceptos, «lo económico en sentido amplio» y «lo económico en sentido estricto», los introduce Mises para explicar la formación de los precios. Si aceptamos la definición neoclásica de comportamiento económico, muchos de los precios que se pagan tendrían como causa un comportamiento no-económico. Esto es así, porque toda persona, según la teoría clásica, actúa

29 Ibid, p. 180

30 Para un análisis comparativo de la obra de Mises y el modelo neoclásico del homo oeconomicus puede consultarse J. Aranzadi (1999a).

31 Véase Mises (1981) p. 157. 
económicamente sólo si compra en el sitio más barato y vende en el más caro. Pero, continúa Mises, es fácilmente refutable esta supuesta racionalidad económica.

Consideremos el siguiente ejemplo: una persona que vive en un territorio políticamente disputado, por ejemplo, Checoslovaquia. Esta persona es un nacionalista alemán que quiere comprarse toda la parafernalia militar para inscribirse en una organización atlético-militar. Si pudiendo hacer sus compras en una tienda regentada por un checo, más baratas que en una tienda regentada por un alemán, y decide comprar en la segunda, deberíamos concluir que actúa antieconómicamente. ¿Es esto correcto? No, ya que la teoría clásica era capaz de explicar sólo la acción del hombre de negocios y era incapaz de explicar todo aquello que fuera más allá, «su pensamiento estaba orientado hacia la contabilidad, la expresión máxima de la racionalidad del empresario». ${ }^{32}$ Para Mises, «el hecho es que la moderna teoría económica empieza por las valoraciones subjetivas del actor y la acción gobernada por dichas valoraciones». ${ }^{33}$

Queda así claro que, para Mises, toda explicación de los precios ha de ampliar su ámbito para considerar como causa económica cualquier estado de insatisfacción percibida por el actor y que conscientemente perciba la existencia de medios para hacerla desaparecer. En el ejemplo del alemán, la insatisfacción es la situación política de la minoría alemana en los Sudetes, y el medio de solucionarlo es ayudar a un compatriota comprando en su establecimiento. Estas características, que explican la formación de cualquier precio, son los requisitos de toda acción humana. Por lo tanto, el ámbito de «lo económico» abarca toda acción humana. «Por medio de su subjetivismo la teoría moderna se convierte en ciencia objetiva. No realiza juicios de valor sobre las acciones; y explica los fenómenos de mercado no so-

\footnotetext{
32 Op. cit., p. 175

33 Op. cit., p. 10.
} 
bre la base de acciones correctas, sino sobre la base de acciones dadas.» ${ }^{34}$

Dada esta explicación, es pertinente preguntarse: ¿consideraba Mises la posibilidad de ampliar el cálculo económico a todo ámbito de la acción humana? O en sus propias palabras, ¿es posible que «lo económico en sentido estricto llegue a englobar «lo económico en sentido amplio»?

Su respuesta es clara: «[E]s absurdo querer aplicar los elementos de este cálculo [coste-beneficio] a problemas distintos. Uno no debe extenderlos a res extra commercium. Uno no debe intentar por medio de ellos incluir más que la esfera de lo económico en sentido estricto. Sin embargo, esto es precisamente lo que intentan aquellos, al averiguar el valor monetario de la vida humana, las instituciones sociales, etc.; o quienes con investigaciones de gran sofisticación intentan determinar en términos monetarios de nuestro dinero tipos de cambio del pasado reciente, por no mencionar los del pasado remoto. ${ }^{35}$

La impresión es que Mises tenía clara la separación entre aquellas acciones sujetas al cálculo económico y el resto de acciones. Las primeras, «lo económico en sentido estricto» eran las acciones productivas o instrumentales en su ámbito de mercado o cataláctica. Estas acciones participaban del axioma de la acción humana y sus categorías estudiadas por la teoría general de la acción humana o praxeología. La teoría general de la acción engloba y supera a la economía. Pero Mises no delimitó en ningún trabajo la frontera entre ambas esferas. Nunca especificó qué acciones humanas no están ni estarán sujetas a cálculo económico. Lo que en nuestra opinión sí es cierto, es que Mises, ya en esta obra, no quedó convencido de su clasificación y restringe la economía como ciencia a la esfera de «lo económico en sentido estricto». Esta conclusión se desprende del siguiente

\footnotetext{
${ }^{34}$ Op. cit., p. 180

35 Op. cit., p. 159
} 
texto: «la investigación de los factores determinantes [de los valores] es la tarea de otras ciencias, no la de la economía. La economía es la ciencia de la cataláctica». ${ }^{36}$

Esto es cierto. Pero también lo es que, si quiere explicar la economía como parte de la teoría de la acción, es necesario discernir entre ambos ámbitos.

\section{Relación entre lo económico en «sentido amplio» y en «sentido estricto»}

La inexistencia de un criterio de demarcación entre las dos esferas de «lo económico» es un tema que Mises vuelve a tratar en La Acción Humana. Las dificultades con que se tropieza al tratar el ámbito de «lo económico» no provienen de que haya incertidumbre respecto a cuáles sean los fenómenos que deban examinarse. La economía como ciencia, en palabras de Mises, «aspira a analizar los precios monetarios de los bienes y servicios que en el mercado se intercambian». ${ }^{37}$

El ámbito de «lo económico» se ciñe al intercambio de bienes y servicios utilizando el cálculo monetario. Es estrictamente «lo económico en sentido estricto». Los problemas surgen en el mismo análisis de los fenómenos de mercado. Es necesario salirse de la órbita estricta del mercado. En una transacción de mercado entran elementos no materiales que son esenciales para el análisis del fenómeno de mercado. Tal como hemos explicado en el apartado anterior, el conocimiento, los modos de habérselas el actor con las cosas, es decir, la cultura, y las personas son elementos constituyentes y determinantes del intercambio, pero no son reducibles al bien o servicio intercambiados. Concluye Mises: «[R]esulta harto difícil trazar una neta frontera

\footnotetext{
${ }^{36}$ Op. cit., p. 168

37 Véase Mises (1995) p. 285.
} 
entre las acciones que deben quedar comprendidas dentro del ámbito de la ciencia económica en sentido estricto (en sentido estrecho), y las que deben ser excluidas, pues la economía fue, poco a poco, ampliando sus primitivos horizontes hasta convertirse en una teoría general que abarca ya todo tipo de acción humana. Se ha transformado en praxeología. Por eso resulta difícil precisar, dentro del amplio campo de la praxeología general, los límites concretos de aquella más estrecha disciplina que se ocupa sólo de las cuestiones estrictamente económicas.» ${ }^{38}$

Mises concibió la economía como una ciencia que «no trata sobre cosas y objetos material; trata sobre los hombres, sus apreciaciones y, consecuentemente, las acciones humanas que de aquéllas se derivan $» \cdot{ }^{39}$ Esta definición implica que para estudiar los fenómenos de mercado hay que salirse de su marco estricto y analizarlos desde las personas que los realizan. Cada paso en la comprensión de la realidad de la persona ha supuesto un avance en la economía. Pero que el avance de la economía se produzca por una incardinación de los fenómenos económicos dentro de una teoría general de la acción no implica que todo acto humano sea reducible a términos monetarios.

Por lo tanto, para separar con nitidez ambos ámbitos utilizaremos el siguiente esquema:

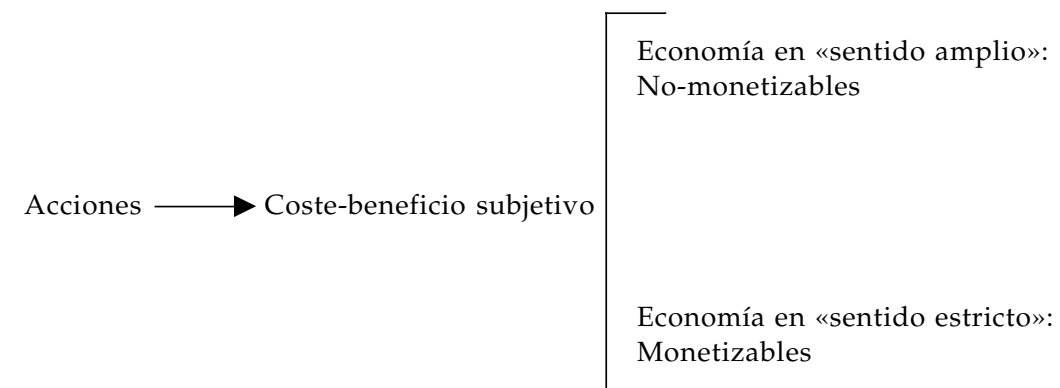

38 Op. cit., p. $283-84$

39 Op. cit., p. 111: «Economics is not about things and tangible material objects; it is about men, their meanings and actions», Human Action, cit., p. 91. 


\section{La estructura de la teoría de la acción misiana}

Es necesario para la explicación de los fenómenos de mercado estructurar una teoría general de la acción. Tarea a la que Mises se dedica en las dos primeras partes de La Acción Humana. Las cinco restantes son deducciones de las leyes económicas. Como él mismo dice, cualquier ampliación en su sistema teórico de la acción es la base para mejorar la teoría económica y su metodología.

La estructura de la primera parte es un análisis de la esencia de la acción. «El punto de partida de la praxeología no consiste en seleccionar unos ciertos axiomas ni en preferir un cierto método de investigación, sino en reflexionar sobre la esencia de la acción.» ${ }^{40} \mathrm{El}$ método es reflexionar sobre los componentes que en toda acción están presentes para que ésta emerja. ¿Cuál es, entonces, la causa irreductible para que se produzca la acción? La propia categoría de acción. Si una persona quiere negar este principio realiza una volición consciente. Por definición, toda conducta consciente es una acción. Por lo tanto, concluye Mises, para negar la categoría de acción dicha persona ha actuado. La acción es un axioma; es irreductible a otras causas. Es una condición necesaria de nuestro conocimiento.

Por lo tanto, el primer punto sobre el que se estructura la teoría de la acción humana de Mises es la acción humana como presupuesto irreductible. Es un principio autofundante. El axioma de acción tiene un significado bien definido. Para superar la visión clásica del homo oeconomicus clásico, Mises busca un principio económico que no radique ni en la elección de los medios, ni en la elección de los fines. Radicando el nuevo principio económico en la inerradicable realidad de toda acción: el hombre tiene que elegir entre las distintas alternativas de acción que se le presentan. El principio económico es la realidad primigenia

\footnotetext{
${ }^{40}$ Op. cit., p. 48.
} 
de toda acción. Para actuar, hay que elegir entre distintas posibilidades. Esto supone que:

1. Toda acción cumple el principio económico.

2. ${ }^{\circ} \mathrm{Si}$ el principio económico no es un criterio de asignación de medios a fines, la elección de los medios depende de la apreciación subjetiva del actor sobre su adecuación para la consecución del fin. Por lo tanto, toda acción es racional.

Sobre el axioma de acción inserta Mises dos elementos. El primero como requisito de acción o categoría básica praxeológica; el segundo como factor praxeológico. Nos referimos a la causalidad y al tiempo, respectivamente.

\section{a) La causalidad}

Aunque la acción no se puede reducir a otra causa, antes de actuar el hombre ha de percibir una situación de insatisfacción. Escribe Mises: «El hombre, al actuar, aspira a sustituir un estado menos satisfactorio por otro mejor. $\gg^{41}$ Siempre ha de preferir un estado a otro. La indiferencia sólo se produciría en el ser plenamente satisfecho que careciera de motivos para variar de estado. ${ }^{42}$

Aun percibiendo ese estado insatisfactorio, el hombre puede no actuar. ¿Cuándo ocurre esto? En palabras de Mises, «cuando el hombre no advierte mentalmente la existencia de cierta conducta deliberada capaz de suprimir o, al menos, de reducir la incomodidad sentida. Sin la concurrencia de esta circunstancia, ninguna actuación es posible; el interesado ha de conformarse con lo inevitable. ${ }^{43}$ Llegados a este punto, tenemos al individuo con una insatisfacción. Quiere un cambio en su situación y considera que existen los medios para cambiarla. Tendrá que

\footnotetext{
${ }^{41}$ Op. cit., p. 18.

42 Op. cit., p. 18.

${ }^{43}$ Op. cit., p. 18.
} 
descubrir las relaciones causales que provocan cambios. Afirma Mises: «El actuar implica y presupone la categoría de causalidad.» ${ }^{44}$ La categoría de medios y fines presupone la relación causa-efecto. Esta relación es responder a la pregunta: «¿Dónde y cómo debo intervenir para desviar el curso que los acontecimientos adoptarían sin esa mi interferencia capaz de impulsarlos hacia metas que satisfacen mejor mis deseos?» ${ }^{45}$

El hombre ha de conocer la relación causal para toda acción. Pero esto no implica que conozcamos a ciencia cierta la causa de todo fenómeno. El principio de causalidad se ha planteado en la búsqueda de la regularidad de los fenómenos, en la búsqueda de leyes: si A, entonces B. Ahora bien, dado que nuestro conocimiento es parcial, tendremos que establecer la ley en términos estadísticos. Diremos: si A, entonces B en el $70 \%$ de los casos, C en el $30 \%$ restantes. Los problemas filosóficos, epistemológicos, metafísicos de la causalidad y la inducción imperfecta quedan fuera del ámbito de la praxeología. Concluye Mises: «Interesa tan sólo a nuestra ciencia dejar sentado que, para actuar, el hombre ha de conocer la relación causal existente entre los distintos eventos, procesos y situaciones.» ${ }^{46}$

\section{b) El tiempo}

¿Cuál es la relación entre la acción y el tiempo? Partiendo del axioma de acción, su prerrequisito era la existencia de una insatisfacción y el deseo de cambiar esa situación. Quien actúa distingue entre pasado, presente y futuro. Esta diferencia en términos filosóficos no es adecuada. Todo momento presente se hunde en el pasado. No es más que una tenue línea entre el futuro y el pasado. Quien actúa distingue entre un tiempo antecedente a la acción, el pasado; un tiempo de acción, y un tiempo consecuente

\footnotetext{
${ }^{44}$ Op. cit., p. 27.

45 Op. cit., p. 28.

${ }^{46}$ Op. cit., p. 29.
} 
a la acción, el futuro. De tal forma que la relación causal antecedente-consecuente la percibimos en esta secuencia temporal. $\mathrm{Si}$, por un lado, la acción implica el deseo de un cambio, la causalidad es necesaria para relacionar los recursos que pueden producir este cambio. La acción y la causalidad van íntimamente unidas. Por otro lado, la relación causal antecedente-consecuente se presenta en una temporalidad procesal. La causalidad y la temporalidad son inseparables. Mises concluye: «Los conceptos de cambio y de tiempo están inseparablemente ligados.» ${ }^{47}$

La estructura fundamental del sistema misiano está terminada. El siguiente esquema representa los elementos que estructuran la teoría de la acción misiana:

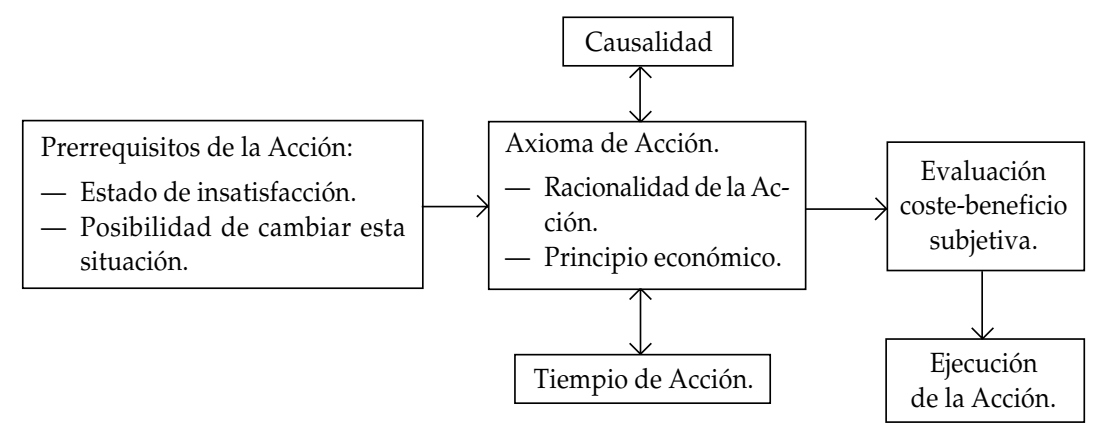

El elemento base es el axioma irreductible de la acción humana. El segundo paso ha sido aclarar los prerrequisitos de la acción: la preferencia. El tercer paso fue analizar cómo este prerrequisito implica la categoría causal para saber discernir en la relación medio-fin. El cuarto y último paso es explicar el carácter secuencial de la relación causal. La conclusión a la que llega Mises es que la acción es una preferencia temporal percibida como una relación medio-fin.

\footnotetext{
47 Op. cit., p. 119
} 
Es el momento de recuperar el esquema de la obra de Parsons presentado más arriba y recapitular lo expuesto hasta el momento.

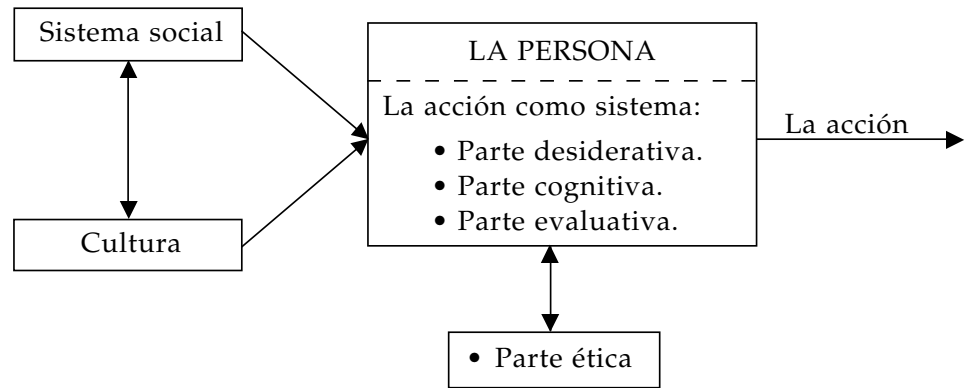

Este esquema representa los elementos analíticos necesarios para obtener una base común a todas las ciencias sociales, según Parsons y sus colaboradores. Consideramos correcta su pretensión, teniendo en cuenta que todas las ciencias sociales tienen el mismo objeto de estudio, aunque delimiten distintos aspectos de dicha realidad. Sea la sociología, la economía, el derecho, la psicología, la historia, la filosofía, todas ellas estudian al hombre en distintos aspectos pertenecientes a un origen común. Es la vida humana este origen común, el cual nos muestra la economía como una realidad surgida de las necesidades humanas. En este proceso en el que el individuo, con los demás hombres (sociedad), con las cosas dotadas de sentido (cultura) genera todo el entramado de bienes y servicios que constituye la economía.

El estudio de la obra de L. von Mises nos ha permitido comprobar cómo desde la teoría económica se ha constatado la necesidad científica de ampliar las bases antropológicas que sustentan los modelos teóricos y comprobar cómo la obra teórica de Mises es perfectamente compatible con el esquema de Parsons. Es decir, de una realidad común es perfectamente esperable que los modelos teóricos desarrollados por grandes científicos que 
desarrollan sus obras desde áreas afines, pero autónomas, converjan. Analicemos el siguiente esquema:

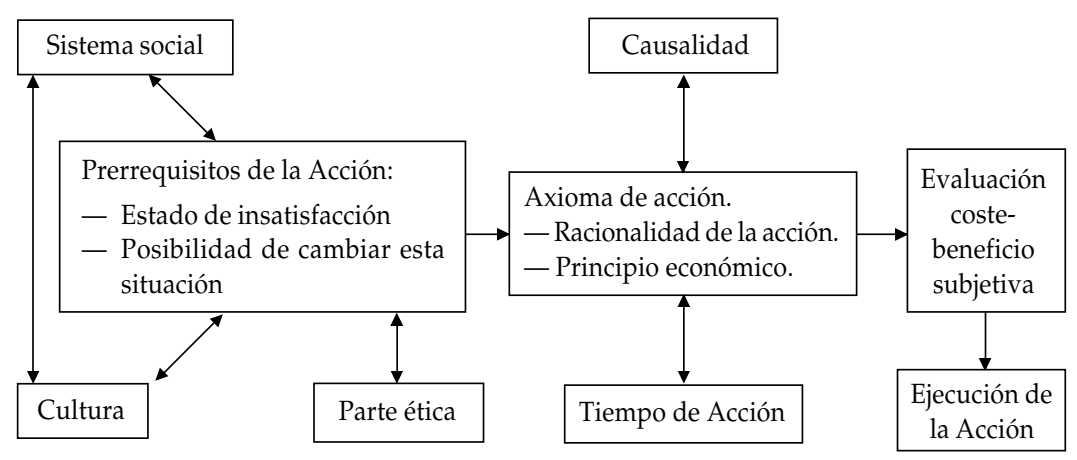

Este esquema nos permite comprobar la riqueza teórica que obtenemos al adoptar una visión común dentro de las ciencias sociales. La interdisciplinariedad alumbra el marco común de todas las ciencias sociales. Las obras de Parsons y Mises nos ofrecen un marco teórico muy rico y fructífero para afrontar problemas de cualquier ciencia social, y la economía en particular. Desde el punto de vista de la teoría económica, este esquema nos permite observar el acto económico más simple, sea una transacción de mercado, como el resultado de un proceso. $\mathrm{Si}$ damos de lado a dicho proceso, si no nos centramos en él, nos será muy difícil comprender qué es realmente. Porque el fenómeno económico observado, es decir, una transacción de mercado, es para cada uno de los participantes un acto económico asignativo. Cada actor ha decidido el fin a conseguir y ha evaluado la adecuación de los medios para la consecución del fin. ${ }^{48}$ Cada agente, utilizando los precios, valora los medios y decide cuál es el intercambio ventajoso para él. El hecho observado es el intercambio de unos bienes por dinero. Esta interpretación

48 Etimológicamente, asignar procede del latín ad signare, que significa fijar o señalar lo que a una persona o cosa corresponde. Por lo tanto, estrictamente hablando, la asignación se produce cuando se ha decidido el fin. 
considera el fenómeno económico como acto asignativo; como un hecho histórico en el cual se han intercambiado unas cantidades de bienes por unas cantidades de dinero. Lo cual es cierto y nos permite afirmar que en todo fenómeno económico, considerado como hecho histórico, existe una relación entre cantidades de dinero y cantidades de bienes.

Pero el fenómeno económico es algo más complejo y radical que el mero intercambio de bienes por dinero. Este intercambio histórico es la plasmación de un elenco de elementos que han intervenido en su constitución y ejecución. Para que el intercambio se produzca, cada persona ha de percibir una situación de insatisfacción y la posibilidad de cambiarla realizando el intercambio. Antes de realizar el intercambio, cada persona evalúa su coste y el beneficio que le otorgará la posesión del bien intercambiado para la consecución del fin. Si sólo consideramos el intercambio en sí, la realidad que lo originó no aparece reflejada. El porqué de un precio parte de considerar que las personas que intervienen en el intercambio persiguen fines. Fines que son cosas, sean materiales o inmateriales, que son deseables y cuya posesión supone un cambio en el estado de insatisfacción previo al intercambio. Pero, por sí sola, la insatisfacción no desencadena el intercambio. Cada persona tiene que percibir la posibilidad de hacer el intercambio. Por muy insatisfactoria que sea una situación, si no sabemos cómo cambiarla, poco podemos hacer.

La insatisfacción originaria se plasma en la consecución de un fin que supone un cambio de situación. El conocimiento no sólo activa la posibilidad del intercambio, sino que permite, mediante el cálculo de coste-beneficio monetario, evaluar si los medios de que dispone cada persona son adecuados para la consecución del fin. Una vez que todos los elementos del esquema planteado en este apartado han intervenido, se produce el intercambio, que es el fenómeno observado. El acto observado es el resultado de la intervención de tres tipos de elementos, ya señalados por Parsons: 
$1 .^{\circ}$ Elementos desiderativos que están presentes en los prerrequisitos de la acción.

2. ${ }^{\circ}$ Elementos cognitivos, presentes en el axioma de acción.

3. ${ }^{\circ}$ Elementos evaluativos, presentes en la evaluación coste-beneficio de los medios.

El hecho de observar el intercambio no se explica por constatar las circunstancias en las que se ha plasmado. Si decimos que el precio de un kilo de patatas es 6 euros, no estamos mencionando las causas que lo han originado ${ }^{49} \mathrm{El}$ intercambio como acto observado se ha de explicar por la intervención de los tres tipos de elementos que lo originan y determinan.

La evaluación de los medios permite asignarlos a la consecución del fin. Mises considera que a la economía no le compete catalogar los fines que se persiguen al intercambiar bienes. Queda a la economía explicar cómo se adecuan los medios a los fines. El único problema, en apariencia, es buscar los medios más adecuados para lograr el fin. Dice Mises: «Los actos mentales que determinan el contenido de una elección se refieren ya sea a fines últimos o a los medios para lograr estos fines. Los primeros son llamados juicios de valor. Los segundos son decisiones técnicas derivadas de proposiciones acerca de hechos. $\nu^{50}$ Pero la evaluación no sólo actúa sobre los medios, también sobre los fines. Mises es consciente de que los fines que se persiguen pueden variar: «Tan pronto como las personas se atreven a poner en duda y a examinar un fin, ya no lo consideran como tal, sino que lo tratan como un medio para alcanzar un fin aún más alto. El fin último está más allá de cualquier examen racional. Todos

49 Este intento de explicación es comparable al estudioso de la medicina que explica la existencia de la enfermedad por la fiebre. La fiebre es la constatación del hecho de la enfermedad, es la constatación empírica externa de su existencia. Pero ni explica cómo se originó ni cómo curarla, lo cual es fundamental no sólo para el médico, sino también para el enfermo.

${ }^{50}$ Véase Mises (1969) p. 12. 
los otros fines son provisionales. Se transforman en medios tan pronto como se les compara con otros fines o medios. ${ }^{51}$

Este párrafo seleccionado apunta a la esencia del acto económico. La asignación de los medios no supone que el deseo y la valoración de otros fines estén desactivados. Las tres categorías de elementos: desiderativos, cognitivos y evaluativos están siempre activos. Los fines son considerados como tales mientras la valoración no considere pertinente un cambio de ellos. Los fines y los medios del acto asignativo no son realidades externas al actor que estén determinadas por una legalidad externa a la persona. Es la persona quien en las propiedades reales de las cosas externas cree descubrir la posibilidad de obtener un fin mediante su utilización. El fin y los medios son posibilidades activas que la persona constituye sobre las propiedades reales de las cosas. Es decir, el acto asignativo es activo, tiene dinamismo.

La asignación se produce porque el actor ha mantenido activado un fin durante un periodo de tiempo, considerando que es el máximo beneficio que puede obtener con los recursos a su alcance. Que se produzca el fenómeno del intercambio a través del dinero, es el resultado de un comportamiento conducente a la consecución del fin deseado. Comportamiento que la persona voluntariamente mantiene a lo largo del tiempo y que supone la justificación del fin.

Los cambios que se producen por el mero paso del tiempo introducen nueva información que la persona evalúa. Tal como define Mises el axioma de acción, la persona actúa porque quiere cambiar una situación insatisfactoria por otra más satisfactoria. El acto asignativo es activo porque la persona prefiere los de mayor valor a los de menor valor. La coherencia lógica implica que para entender el acto asignativo hemos de considerar que la persona persigue un fin. Pero que la persona actúe con un fin no supone que el fin perseguido sea siempre el

51 Op. cit., p. 14. 
mismo. En palabras de Mises: «Si nuestra valoración cambia, también habrá de variar nuestra actuación. Modificadas las circunstancias, carecería de sentido permanecer fiel a un plan de acción anterior. Un sistema lógico ha de ser coherente y ha de hallarse exento de contradicciones por cuanto supone la coetánea existencia de todas sus diversas partes y teoremas. En la acción, que forzosamente se produce dentro de un orden temporal, semejante coherencia es impensable. La acción ha de acomodarse al fin perseguido y el proceder deliberado exige que el interesado se adapte continuamente a las siempre cambiantes condiciones. ${ }^{52}$

Estas consideraciones nos llevan a la esencia del fenómeno económico que observamos; el hecho histórico del intercambio es el resultado de un proceso de creación y descubrimiento de fines y medios, su constante evaluación y ejecución. Cada acto económico tiene plena explicación como parte integrante de un proceso dinámico en el que intervienen elementos desiderativos, cognitivos y evaluativos de la persona en su entorno socio-cultural. No hay explicación plena del acto, si no es dentro del proceso que lo generó. Por lo tanto, el fenómeno económico adquiere su pleno significado al considerarlo, no como un acto aislado, sino dentro del proceso activo de la persona que lo ejecuta, tal como está expuesto en el esquema de este apartado. Este carácter dinámico del acto económico pone de manifiesto que dichos fenómenos son realmente partes constitutivas de un proceso dinámico más complejo: la acción humana.

\footnotetext{
52 Véase Mises (1995) p. 169.
} 


\section{LA PERSONA Y SUS POSIBILIDADES DE ACCIÓN}

Llegamos al último apartado y, como era de esperar, el análisis de la estructura de la acción nos ha devuelto a la persona y sus posibilidades de acción. Si nuestros razonamientos son correctos, nos encontramos en situación de aportar una serie de indicaciones sobre la estructura de los elementos cognitivos, desiderativos y evaluativos que constituyen el núcleo de la acción individual. Las posibilidades de acción de la persona son el resultado de la gestión inteligente de la realidad. La realidad queda expandida por las posibilidades que gestiona la inteligencia al integrarla en proyectos humanos. El hombre inventa posibilidades, gestando y gestionando la irrealidad del proyecto. Si bien es cierto que lo posible se basa en las propiedades reales de las cosas, no se puede reducir a ellas, porque lo posible, que aún no existe, surge de la acción de la inteligencia sobre la realidad.

El objetivo de este apartado es explicar la proyectividad humana como la capacidad de crear información, elaborarla y producir respuestas eficaces. Proyectar es anticipar una meta. Toda persona, al emprender un proyecto, acomete una empresa. El proyecto es una irrealidad; es una proyección del actor. Éste se proyecta hacia el futuro trascendiendo el presente. El proyecto es una línea de acción a punto de ser emprendida; activa, motiva y dirige la acción. En el origen de todas las ocurrencias proyectivas hay un deseo de actuar. Toda persona, por rutinaria que sea, emprende un proyecto fuera de su zona de desarrollo próximo. El objetivo se percibe de una manera difusa, poco clara. Más que un conocimiento preciso y claro, es una sensación de falta. ¿Qué conoce de un objetivo una persona cuando se propone algo? Siempre se parte de ideas muy vagas. J. A. Marina ${ }^{53}$ señala que el objetivo puede ser cualquier realidad sugerente en la que se

${ }^{53}$ Cf. J.A. Marina (1993). 
barruntan muchas posibilidades. Volvamos a resaltar que estas posibilidades no son propiedades de las cosas, sino operaciones incoadas por las personas que cambian el significado de las cosas. Se convierten en sugerentes, interesantes, prometedoras. Percibimos mejoras de la situación en la que nos encontramos. Como señala Mises, ${ }^{54}$ en el origen de cada acción está la percepción de una insatisfacción y el conocimiento, por muy difuso que sea, de una situación más satisfactoria que se convierte en el objetivo de nuestra acción.

El fin de cualquier acción tiene dos características esenciales:

1. ${ }^{a}$ Todo objetivo es la percepción de carencia, unido al deseo de actuar. La percepción de la meta anticipa el camino a seguir para alcanzarlo. En todo proyecto, la persona se sale de lo dado, de lo estadísticamente previsible. Se adentra en lo irreal, en lo que todavía no existe. Se pretende lo nunca visto. ${ }^{55}$ La acción humana, al proyectarse, se sale de lo dado; no se pretende una repetición del pasado, sino su mejora: se amplía la realidad personal de cada actor con posibilidades que hasta el momento nunca había intentado. El proyecto es someter la acción humana a la consecución de una irrealidad que todavía no existe, pero que el actor encuentra sugerente.

2. ${ }^{a}$ El objetivo es siempre una percepción individual. La misma realidad es concebida de manera totalmente distinta por personas diferentes. La característica de la creatividad es ver posibilidades donde los demás no ven nada. ${ }^{56}$ Este fin que se proyecta en el futuro ejerce sus efectos en el presente. No hay un salto infranqueable entre el fin de la acción y el presente. El proyecto

54 Véase el tercer apartado de este trabajo.

55 J.A. Marina cita como ejemplo el afán de Valle-Inclán de unir palabras que no habían estado antes juntas. Marina (1993) p. 152.

56 Un ejemplo claro es el ofrecido por J.A. Marina sobre Einstein: «El mismo Einstein, reflexionando sobre su obra, dijo que durante todos esos años tenía un sentimiento de dirección, de ir en línea recta hacia algo concreto. Es muy difícil de describir ese sentimiento, pero yo lo experimentaba como una especie de sobrevuelo, en cierto sentido visual.» Ver J.A. Marina (1993) p. 135. 
es el plan que hace actual y real nuestro fin que, de entrada, nos aparece lejano e irreal. Entre el futuro y el presente se establece el nexo que dará realidad a nuestras aspiraciones. Por lo tanto, el futuro no es algo utópico, que no tiene lugar en este mundo. Por el contrario, la nota esencial del objetivo que perseguimos es que sea factible, que se pueda alcanzar. De esta manera, podemos afirmar que el objetivo que nos marcamos en el futuro no es un porvenir, sino un porhacer. ${ }^{57}$

Una vez que nos decidimos por un fin, adecuamos los medios a su consecución. Podemos, por lo tanto, afirmar que proyectar es un proceso asignativo. Pero, teniendo siempre en cuenta que lo esencial del proyecto es su carácter dinámico. No podemos desligar el carácter asignativo del procesal y considerar que los fines de la acción están dados. Esta separación supone una reducción antropológica fundamental. Si adoptamos la hipótesis de fines dados, olvidamos que nunca existe un único curso de acción; olvidamos que siempre las posibilidades son plurales; que nunca hay una única alternativa de acción. Por esta razón, hablamos de la creación de posibilidades en plural. El hombre es el animal que posee futuro; siempre se enfrenta a múltiples posibilidades de acción. El problema al que hace frente es determinar qué es lo que puede hacer en cada alternativa; determinar el alcance $u$ objetivo de cada posibilidad y compararlas entre sí. Aunque esta idea parece obvia, es importante incidir en que la estructura dinámica de la acción, por su propio dinamismo, determina múltiples fines que compiten entre sí. En otras palabras, no existe la acción en singular, sino el sistema plural de fines y medios.

Dentro de los distintos fines a su alcance, se decide por el que valora más. Pero en cuanto cambian las circunstancias puede

57 Esta misma idea la expresa magistralmente el profesor Julián Marías con las siguientes palabras: «Mi vida no es cosa, sino un hacer, una realidad proyectiva, argumental, dramática, que propiamente no 'es', sino 'acontece'.» Cursiva en el original. Ver J. Marías (1996), p. 126. 
cambiar la valoración y elegir otro fin. Como señala Mises: "Cuando se han modificado las propias valoraciones, permanecer adheridos a unas ciertas normas de acción anteriormente adoptadas, en gracia sólo a la constancia, no sería una actuación racional, sino pura terquedad. La acción sólo puede ser constante en un sentido: en preferir lo de mayor a lo de menor valor. ${ }^{58}$ Si desligamos el fin de su estructura generadora, no realizamos una simplificación intranscendente; realizamos un cambio de base en el estudio de los problemas humanos, abandonamos al hombre de carne y hueso y nos centramos en el homo oeconomicus. En la economía praxeológica es fundamental ligar los fines a la estructura de la acción. La multiplicidad de los mismos y su carácter dinámico aconseja su estudio desde la teoría de la acción. Si partimos de la visión de los medios y los fines como una estructura dinámica, la función del proyecto es planificar las actividades que hay que ejecutar para la consecución del fin.

El proyecto no es un sueño. En el sueño no hay manera de pasar de la irrealidad a la realidad. En el proyecto las cosas reales constituidas en recursos nos mantienen en la realidad. El proyecto está siempre condicionado por los recursos de la acción. Gran parte de la tarea creadora va a consistir en gestionar las restricciones, siendo el tiempo una de las principales. Henri Bergson tiene estas bellas palabras sobre el tiempo: «El tiempo es lo que impide que todo esté dado de un golpe. Retarda o, mejor, es demora. Él debe, por lo tanto, ser elaboración. ¿No será vehículo de creación y de elección? ¿No prueba la existencia del tiempo que existe la indeterminación de las cosas? ¿No será el tiempo esta indeterminación misma? $\gg^{59}$ En el estudio del tiempo hay que diferenciar dos aspectos: la historicidad de la persona y la estructura sinóptica del proyecto.

\footnotetext{
58 Mises, (1995) p. 124

59 H. Bergson, (1963), p. 1333.
} 


\section{a) La historicidad de la persona}

La primera aproximación a la realidad tempórea es reconocer que la vida humana tiene una duración; se entiende que la vida dura una serie de años. Pero es duración con un orden bien determinado. El tiempo tiene pasado, presente y futuro. Como señala Mises, lo único que estamos afirmando es que: «Quien actúa distingue el tiempo anterior a la acción, de un lado, el tiempo consumido por la misma, de otro, y el posterior a ella, en tercer lugar. No puede el ser humano desendenterse del tracto temporal.» ${ }^{60} \mathrm{El}$ tracto temporal -el antes, el ahora y el después- no solamente es una duración en tres partes, sino que estas tres partes tienen un cierto orden. Antes y después, significan antes y después en la ordenación.

Esta ordenación temporal, no solamente es una ordenación, sino una ordenación en la que en cada momento sólo existe una de las partes: el presente. El pasado ha dejado de existir; el futuro todavía no existe. Cuando la ordenación de los elementos de una magnitud es tal que la anterioridad y posterioridad en el orden significa que lo uno deja de ser lo que es lo otro, entonces es fluente. Señala Mises: «Para la praxeología [...], entre el pasado y el futuro se extiende un presente amplio y real. La acción, como tal, se halla en el presente porque utiliza ese instante donde se encarna su realidad. ${ }^{61} \mathrm{He}$ aquí la clave para entender la historicidad de la persona. ${ }^{62}$ El hombre no vive en el tiempo; su histo-

${ }^{60}$ Mises (1995) p. 120.

${ }^{61}$ Op. cit., p. 121. Esta misma idea del presente la encontramos en H. Bergson, quien comenta: «Se define arbitrariamente el presente como lo que es, cuando el presente es simplemente lo que se hace.» Cursivas en el original. Véase H. Bergson (1963a) p. 291.

${ }^{62}$ El papel fundamental del tiempo fue destacado por el propio C. Menger, fundador de la Escuela Austriaca de Economía. Consúltese al respecto el apartado «Tiempo-error» del capítulo primero de Menger (1997), pp. 120 ss. Sobre este tema, véase el artículo de A.M. Endres (1984), p. 900. Afirma: «El tiempo histórico reina absolutamente en los Grundsätze.» También Max Alter señala: «El proceso de cambio, siendo el proceso causal, sólo es comprensible como un proceso temporal.» Véase Alter (1982). Las cursivas son mías. 
ricidad es algo más radical: el presente del hombre está hecho del pasado y del futuro. La realidad humana no sólo está en el tiempo, sino que el tiempo está en ella. De suerte que el hombre no solamente tiene un pasado y tiene un futuro, como en el mundo físico, sino que está hecho en su presente de pasado y futuro.

La historicidad del hombre, es decir, la fluencia del tiempo implica una dirección. El tiempo fluye del pasado hacia el futuro. Apunta Mises: «La acción influye exclusivamente sobre el futuro [...]. El hombre adquiere conciencia del tiempo al proyectar la mutación de una situación actual insatisfactoria por otra futura más atrayente. $»^{63}$ La fluencia del tiempo significa que el hombre está inexorablemente proyectado al futuro. No hay reversibilidad posible en la historicidad del hombre. Cada momento vivido se convierte en pasado. El ahora del presente ingresa continuamente en el pasado quedando sólo retenido por la memoria. Son los fines que el actor conscientemente proyecta los que ejercen su efecto sobre el presente. Pero este presente se escapa: está constantemente fluyendo. No hay forma de retener el tiempo. La única forma que tiene el hombre de salirse de lo dado, de la fluencia, es representarse mentalmente un esquema que sintetice los pasos que ha de dar para conseguir su objetivo. En otras palabras, el hombre vence al tiempo a través del proyecto.

\section{b) La estructura sinóptica del proyecto}

El tiempo del proyecto es el tiempo con que cuenta el hombre para hacer su vida. El hombre cuenta con el tiempo, con su tiempo, para hacer el proyecto. Esta estructura de contar con el tiempo no es independiente de la fluencia. El hombre es un ser fluyente, independientemente del proyecto. La vida del hombre fluye inexorablemente en una dirección. Es decir, la primera

\footnotetext{
${ }^{63}$ Mises (1995) p. 120.
} 
característica del proyecto es su fluencia. Todo proyecto es una sucesión de actividades. Pero la forma de salirse de esta fluencia es a través de la inteligencia. El actor organiza la información que posee y se representa las actividades que ha de realizar para conseguir su objetivo. En otras palabras, se representa su propia vida como un todo, donde las etapas del proyecto son las partes que conforman su realidad deseada. A esta representación intelectual o proyección que el actor posee la vamos a denominar, siguiendo a Zubiri, estructura sinóptica. ${ }^{64}$

¿Qué es dicha estructura? La estructura sinóptica del proyecto es la forma de escapar de la fluencia. Es una percepción del tiempo del que dispone el hombre para realizar el proyecto. En palabras de Zubiri: «El hombre tiene una inteligencia y una inteligencia en la que por siguiente su fluir tiene dos dimensiones distintas: de un lado, como acto psíquico, está sometida a un fluir, exactamente como todo lo demás: como sus sentimientos y sus voliciones y su vida entera. Es un fluir de actos de una manera indiscernida; cada acto respecto de otros fluye en la unidad del torrente de la conciencia. Esto es verdad. Pero lo que pasa al unísono es que la inteligencia ve precisamente su propia realidad fluente y cuenta con la realidad entera en cuanto tal, y por consiguiente, se abre a la totalidad del campo de lo real en su carácter de fluente. Es el tiempo sinóptico. Esta visión del campo entero de la realidad fluente reobra sobre el momento presente de su fluencia, y este reobrar es justamente el proyecto.» ${ }^{65}$

Así se unen los dos aspectos temporales en el hombre: es fluyente porque es histórico y es proyectivo porque está abierto al futuro. ${ }^{66}$ La proyectividad es el tiempo como posibilidad propia del hombre y de

${ }^{64}$ La idea la he tomado del capítulo XI de su Estructura dinámica de la realidad, cit., titulado «El dinamismo como modo de estar en el mundo», pp. 279-311.

65 Zubiri (1989) p. 307

${ }^{66}$ Señala el profesor Julián Marías: «El tiempo no es mero transcurso o fluencia... el tiempo no se limita a 'pasar', sino que tiene estructura; y ésta no es la simple duración o cuantificación, sino la que impone la realidad proyectiva de la vida.» Véase J. Marías (1995) p. 182. 
su vida. En todo proyecto, el hombre tiene una visión sinóptica, ${ }^{67}$ las distintas etapas que forman el proyecto aparecen ordenadas secuencialmente y ejercen su efecto en el presente de acción. En el párrafo anterior, hemos puesto en cursivas la última frase del texto seleccionado de Zubiri porque expresa con claridad y precisión el nexo que existe entre el futuro proyectado y el presente de acción. La realidad deseada que el actor quiere realizar afecta a su historicidad, a su presente de acción. Esta afección del futuro sobre el presente es el material que maneja la creatividad humana. Esta capacidad creativa no es reducible a la información que maneja el actor, sino que su misión fundamental es manejar información prospectivamente, es decir, generar planes. ${ }^{68}$

La unidad de la estructura sinóptica del tiempo y la fluencia explica el significado de la frase, dar tiempo al tiempo. ${ }^{69}$ Aquí el tiempo funciona dos veces. Desde el punto de vista sinóptico, hay que dejar que el tiempo fluya. Luego, en la fluencia del tiempo las ideas tienen que madurar, tienen que dar de sí. En todo proyecto se intenta ahorrar tiempo. Pero, como señala Mises: todo proyecto se ve «sometido a la servidumbre del demasiado pronto y del demasiado tarde». ${ }^{70}$

La ejecución del proyecto cierra la estructura de la acción. Sea cual sea el tipo de proyecto, su ejecución transforma su marco originario. La ejecución de una acción tiene consecuencias fun-

${ }^{67}$ La idea de estructura sinóptica del proyecto está presente en la obra de Mises. Lo expresa de manera concisa: «El hombre adquiere conciencia del tiempo al proyectar la mutación de una situación actual insatisfactoria por otra futura más atrayente.» Mises (1995) p. 120.

68 El profesor J. Huerta de Soto define el plan como: «La representación mental de tipo prospectivo que el actor se hace de las distintas etapas, elementos y posibles circunstancias que puedan estar relacionadas con su acción.» Ver J. Huerta de Soto (1992) p. 45 , nota 8.

69 Zubiri (1989) p. 307.

70 Mises (1995) Esta cita se toma de la $4 .^{\text {a }}$ edición española (p. 167), porque en la $5 .^{\text {a }}$ y en la $6 .^{\text {a }}$ dicha frase se ha transformado en la siguiente: "sometido a la servidumbre del antes y del después» (p. 122), expresión que, a nuestro parecer, se adecua menos que la citada en el cuerpo del texto a la idea original de Mises. 
damentales sobre la persona que actúa, la sociedad y la cultura. Estas tres dimensiones sólo son separables analíticamente. La realidad observada es la acción individual. Pero acción con otras personas; es decir, acción social. Y acción dotada de sentido, es decir, acción cultural. En la acción se manifiestan todas las facetas de la estructura dinámica de la realidad personal.

\section{REFERENCIAS BIBLIOGRÁFICAS}

Alter, M. (1982). «Carl Menger and Homo Oeconomicus: Some Thoughts on Austrian Theory and Methodology», Journal of Economic Issues, vol. 16, n. ${ }^{\circ}$ 1, marzo de 1982.

ARANZADI, J. (1997).«Ética y Empresarialidad: la Posibilitación de la Persona», documento n. ${ }^{\circ} 40$ del Instituto de Empresa y Humanismo, pp. 3-9.

- (1999a). Liberalismo contra Liberalismo, Unión Editorial, Madrid.

- (1999b). «La división social del trabajo y la realización personal», Papeles de Ética, Economía y Dirección, n. ${ }^{\circ}$ 4, pp. 1-7.

- (2001). «Empresarialidad, creatividad y ética», Papeles de Ética, Economía y Dirección, n. ${ }^{\circ}$ 6, pp. 23-39.

Bergson, H. (1963a). Matière et Mémoire, en Oeuvres. París, PUF. - (1963b). La Pensée et le Mouvant, en Oeuvres, París, PUF.

Buber, M. (1995). ¿Qué es el hombre?, Méjico, FCE.

ENDRES, A. M.(1984). «Institucional Elements in Carl Mengers's Theory of Demand: A Coment», Journal of Economic Issues, vol. 18, n. $^{\circ} 3$.

Huerta De Soto, J. (1992). Socialismo, Cálculo Económico y Función Empresarial. Madrid, Unión Editorial.

Husserl, E. (1991). La crisis de las ciencias europeas y la fenomenología trascendental, Barcelona, Editorial Crítica.

MARÍAS, J.(1995). Antropología Metafísica. $2^{a}$ edición, Madrid, Alianza Universidad, Madrid.

- (1996). Persona, Madrid, Alianza Editorial. 
MARINA, J. A. (1993). Teoría de la Inteligencia Creadora, Barcelona, Anagrama.

Menger, C. (1997). Principios de Economía Política, 2. a edición, Madrid, Unión Editorial.

Millán-Puelles, A. (1974). Economía y Libertad, Madrid, CECA. MISES, L. (1978). Ultimate Foundation of Economic Science: An Essay on Method. 2. ${ }^{a}$ edición, Kansas, Sheed Andrews and McMeel.

- (1969) Theory and History, 2. a edición, New Rochelle, Arlington House. Traducción española, Unión Editorial, Madrid.

- (1981) Epistemological Problems of Economics, New York, New York University Press.

- (1995) La Acción Humana, 5. a edición, Madrid, Unión Editorial. 7. ${ }^{\text {a }}$ edición 2004.

PARSONS,T. y ShILls, E. (1968). Hacia una Teoría General de la Acción, Buenos Aires, Editorial Kapelizz, Buenos Aires.

Polo, L. (1993). Quién es el Hombre, 2. a edición, Madrid, Rialp. Wojtyla, K. (1982). Persona y Acción, Madrid, BAC.

ZubIRI, J. (1989). Estructura Dinámica de la Realidad, Madrid, Alianza Editorial. 